\title{
Prevention and Treatment of Esophageal Cancer in China: Achievements and Challenges-Prevention is the Key
}

\author{
Huimin Zhao $^{\star 1}$, Weiwei Zhang ${ }^{2}$, Donghui Jia ${ }^{1}$, Aiming $\mathrm{Li}^{1}$, and Yangming F Wang ${ }^{\star 2}$ \\ ${ }^{1}$ Department of Thoracic Surgery, No.1 Hospital of BaoDing City, China \\ ${ }^{2}$ College of Life Sciences, HeBei Agricultural University, China
}

*Corresponding author: Huimin Zhao, Department of Thoracic Surgery, No.1 Hospital of Baoding City, Baihua East Road No.966, Lianchi District, HeBei 071000, China, Tel:+8603122096553, E-mail: mouth101@163.com Yangming F Wang, College of Life Science, HeBei Agricultural University, Lingyusi Street No.289, BaoDing City, HeBei, 071000, P. R. China, Tel: +8603127528240, E-mail: shmwym@hebau.edu.cn

Citation: Huimin Zhao, Weiwei Zhang, Donghui Jia, Aiming Li, Yangming F Wang (2017) Prevention and Treatment of Esophageal Cancer in China: Achievements and Challenges-Prevention is the Key. J Cancer Sci Clin Oncol 4(2): 201. doi: 10.15744/2394-6520.4.201

Received Date: October 24, 2017 Accepted Date: December 05, 2017 Published Date: December 11, 2017

\begin{abstract}
Background: The study investigated esophageal cancer etiology and pathology, along with problems associated with surgical treatments.

Methods: Data from the National Cancer Prevention and Control Office and the National Cancer Registry Center (2012) were assessed for information regarding malignant tumor incidence. These data were also used to conduct a mortality analysis and investigate death records pertaining to esophageal cancer patients. We extracted crude and age-specific mortality data and proportional mortality ratios as well as standard mortality data for Chinese and world populations. Esophageal cancer mortality was compared with death statistical data and literature related to esophageal cancer was collected from the Chinese Biomedical Literature Database and the Chinese Journal Network.

Results: The crude mortality rate for esophageal cancer in China was $15.58 / 100,000$ for the period analyzed (21.48/100,000 and $9.37 / 100,000$ for males and females, respectively). The age-standardized mortality rate was $11.51 / 100,000(16.86 / 100,000$ and $6.38 / 100,000$ for males and females, respectively). Esophageal cancer mortality increased with age. In China, squamous cell cancer was the most common disease type and the middle and lower esophagus were the most common sites with respect to disease occurrence. Most patients received surgical treatment for mid- to advanced-stage cancer and the operative mortality rate was $2.32 \% \pm 1.087$. The most common post-operative complication was anastomotic leakage $(2.57 \% \pm 1.087)$ and the 5 -year relative survival rate for esophageal cancer was $43.95 \% \pm 10.247$.
\end{abstract}

Conclusion: Mortality rates for esophageal cancer are decreasing in China. However, Primary and secondary preventions are essential for disease control and early diagnosis and treatment is challenging.

Keywords: Esophageal cancer; Mortality; Etiology; Pathology; Treatment; 5-year survival

\section{Introduction}

Although esophageal cancer has been studied in China since 1959, the country has one of the world's highest incidences of the disease. The first mortality report pertaining to incidences of the disease in China was published in the 1970s. The report showed that esophageal cancer accounted for $22.57 \%$ of all cancer deaths and the disease represented the second leading cause of death from malignant tumors [1]. China's National Office for Cancer Prevention and Control, the National Central Cancer Registry (NCCR), and the National Cancer Institute released a national cancer incidence and mortality analysis in 2012, and the most recent data regarding disease occurrence and mortality rates were released in 2015 [2]. Using these data, we studied esophageal cancer mortality trends in China and assessed etiology and pathology as well as problems with surgical treatment.

\section{Materials and Methods}

The first large-scale census of esophageal cancer in China was under taken in HeNan Province at the end of the 1950s. The resultant data prompted the Chinese government (1964 and 1969) to assemble a national medical team to investigate and prevent esophageal cancer [3]. From 1959 to 1962, a retrospective report on the incidence and mortality of esophageal cancer and a population-based cancer registry reporting system were established. The death report was commissioned in 1978 and the associated data included cross-sectional surveys, as well as case-controlled and prospective-cohort studies. From 1973 to 1975, retrospective surveys of population deaths were conducted in China over three periods: from 1973-1975, from 1990-1992, and 
from 2004-2005 [4-9].The report was released in 2015 and was used along with the international classification of disease-10 (ICD-10) to study C15 esophageal cancer death records and corresponding population data [2]. The latter report contained statistical data from 2014 and included information from 31 provinces. A total of 234 cancer registries submitted data from new cancer cases and cancer deaths, and overall population coverage of 221.4 million was achieved (accounting for $16.43 \%$ of the entire Chinese population).

\section{Results}

The overall mortality data for esophageal cancer in China are shown in Table 1 and the data reveal that the number of deaths resulting from this disease is decreasing. The number of deaths resulting from esophageal cancer is low in individuals under the age of 35. We also observed that mortality rates begin to increase over the age of 35, peaking at 80 years-of-age (Figure 1). The disease occurs most frequently in males and the number of male deaths was lowest in this age group in 2012. In addition, in 2012 mortality was higher for those males aged 50-65 years than in 2004; a similar trend was observed for females (Figure 2). Female mortality from esophageal cancer peaked for women older than 85 years-of-age (Figure 3 ) and overall mortality for men was greater than for women. The data also revealed that since the 1970s, improvements in economic development and quality of life have contributed to decreased mortality from esophageal cancer. In the past 20 years, population mobility has increased in China and many rural individuals have migrated to the city. However, the rural data does not significantly differ from that generated from the city. There are many risk factors for esophageal cancer and a study conducted in Linzhou (HeNan Province), China confirmed that genetic factors, consumption of fermented or pickled foods, and smoking increase the incidence of esophageal cancers (Figure 4) [10-12].

\begin{tabular}{|c|c|c|c|c|c|c|c|c|c|c|c|c|}
\hline & \multicolumn{3}{|c|}{ 1970-1975 } & \multicolumn{3}{|c|}{ 1990-1992 } & \multicolumn{3}{|c|}{ 2004-2005 } & \multicolumn{3}{|c|}{ 2011-2012 } \\
\hline & All & Male & Female & All & Male & Female & All & Male & Female & All & Male & Female \\
\hline $\begin{array}{c}\text { Rate } \\
\left(1 / 10^{5}\right)\end{array}$ & 16.75 & 21.12 & 12.18 & 17.38 & 22.14 & 12.34 & 15.21 & 20.65 & 9.51 & 15.58 & 21.48 & 9.37 \\
\hline $\begin{array}{l}\text { ASRcn } \\
\left(1 / 10^{5}\right)\end{array}$ & 17.10 & 23.10 & 11.60 & 15.02 & 20.35 & 10.01 & 9.98 & 14.32 & 5.75 & 11.51 & 16.86 & 6.38 \\
\hline $\begin{array}{l}\text { ASwld } \\
\left(1 / 10^{5}\right)\end{array}$ & 23.20 & 31.40 & 15.80 & 20.40 & 27.73 & 13.63 & 13.73 & 19.66 & 8.02 & 11.62 & 17.05 & 6.42 \\
\hline $\begin{array}{c}\text { PM } \\
(\mathrm{I} \%)\end{array}$ & 22.57 & 24.98 & 19.21 & 16.05 & 16.39 & 15.44 & 11.19 & 12.13 & 9.51 & 10.62 & 15.63 & 5.82 \\
\hline $\begin{array}{c}\text { Rank order } \\
\text { of causes of } \\
\text { death }\end{array}$ & 2 & 2 & 2 & 4 & 4 & 5 & 4 & 4 & 4 & 4 & 4 & 5 \\
\hline
\end{tabular}

PMI: Proportional mortality indicator

Table 1: Different time esophageal cancer mortality in china

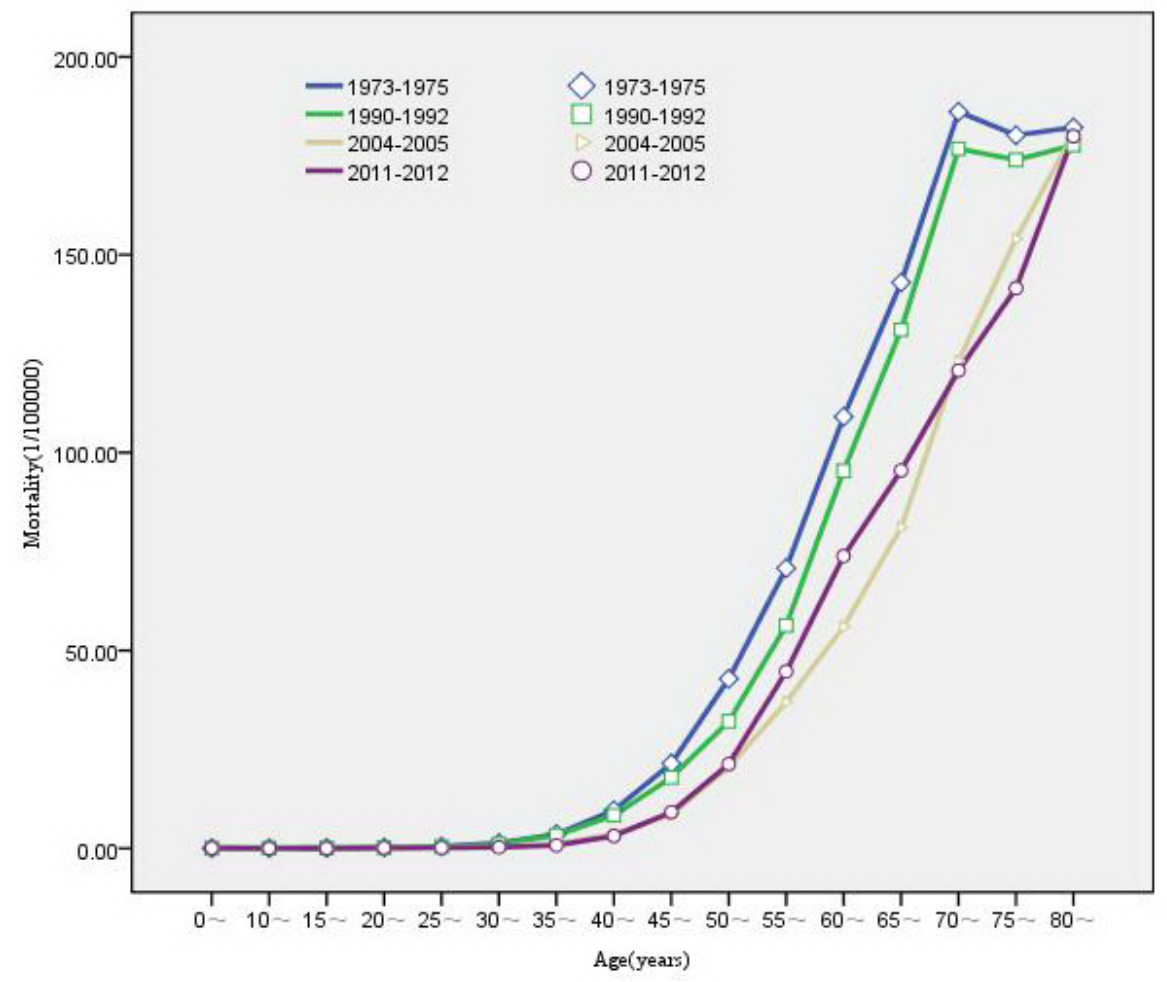

Figure 1: Age-specific esophageal cancer mortality in total at different times 


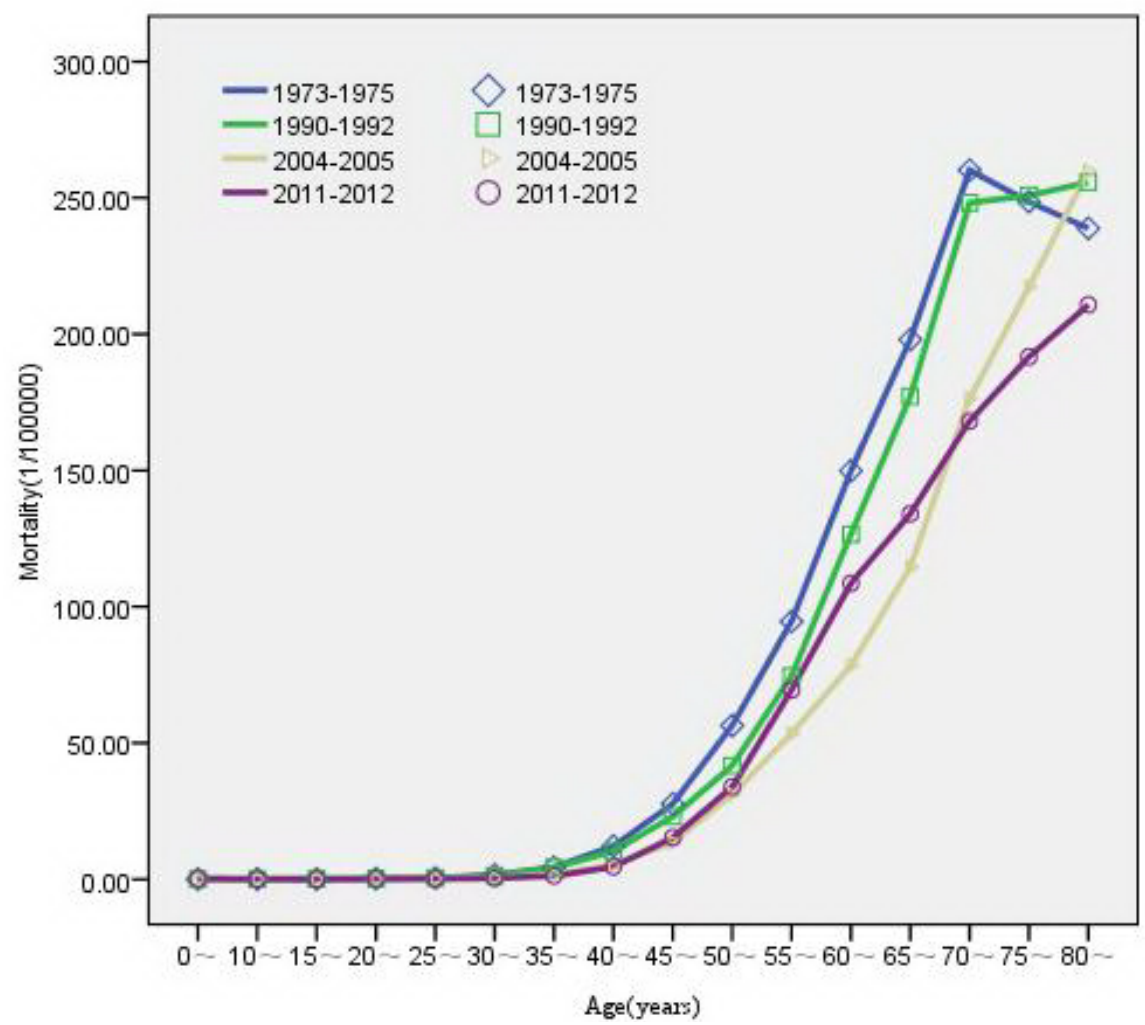

Figure 2: Age-specific esophageal cancer mortality in male at different times

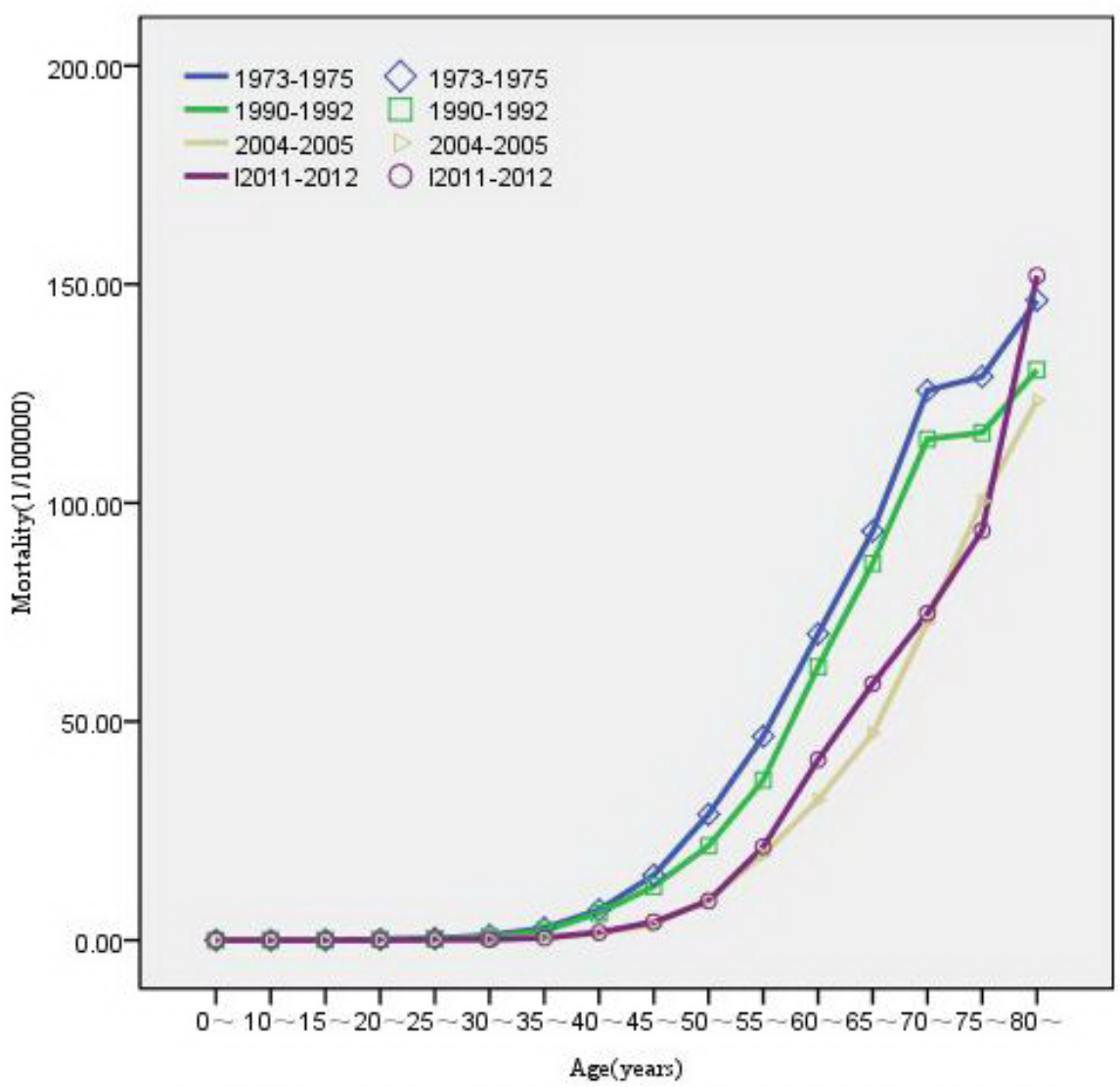

Figure 3: Age-specific esophageal cancer mortality in female at different times

Zhang DH [13] Meta-analysis of 1174 esophageal cancer patients and 988 normal people from the year of 2008 to 1987 showed that the Human papillomavirus (HPV) infection rate of esophageal cancer tissues was 4.29 times higher than that of normal esophageal tissues (95\% CI:2.38-7.70). The average infection rate of HPV in esophageal cancer tissue and normal esophageal 
tissue was significantly higher in the high incidence area than that in the low incidence area $\left(59.26 \% \mathrm{vs} 34.66 \%, \chi^{2}=66.05\right.$, $P<0.001,42.50 \%$ vs $\left.15.82 \%, \chi^{2}=66.02, P<0.001\right)$. Therefore, HPV infection is an important factor in the high incidence of esophageal cancer in China (Table 2).

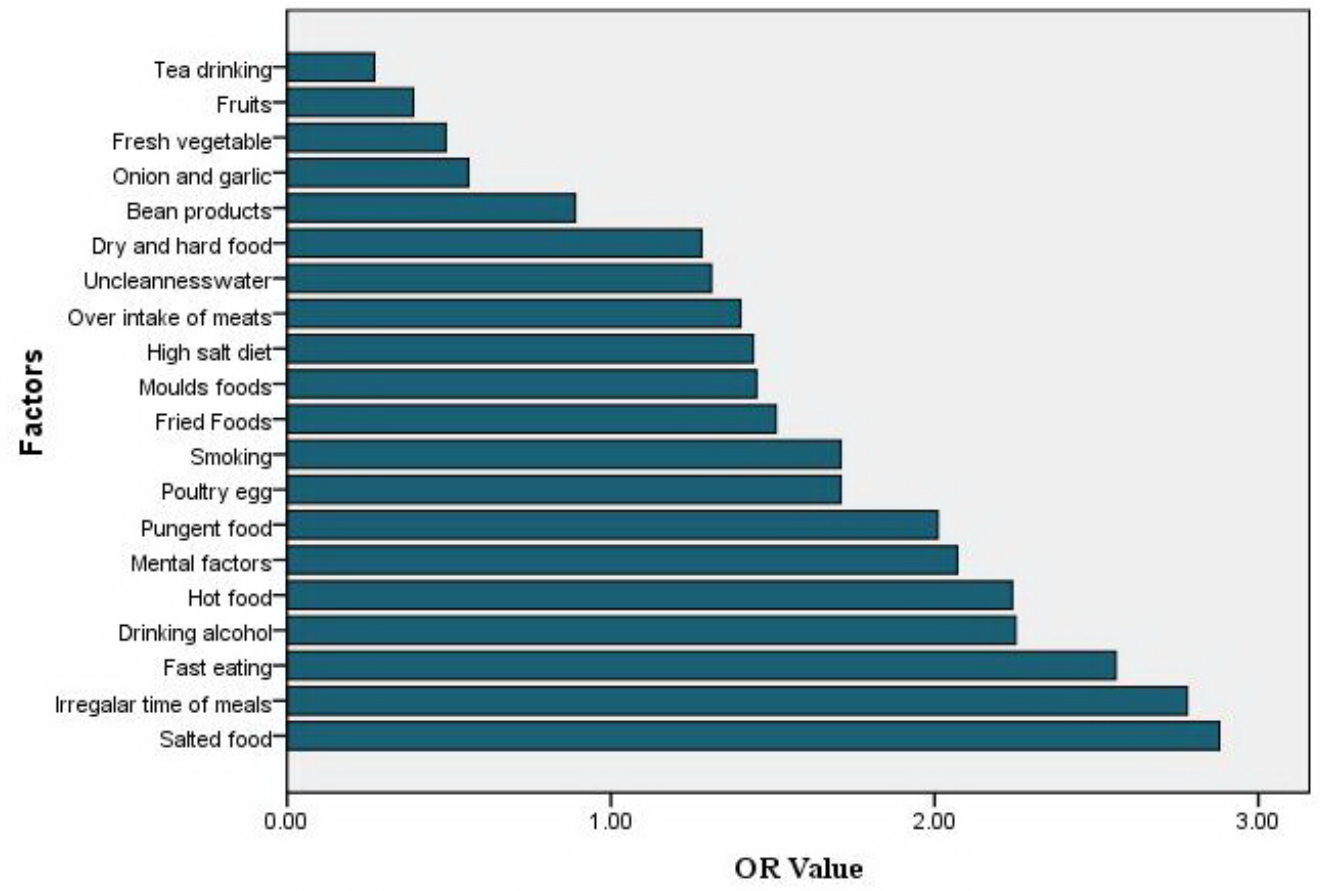

Main effect factors of esophageal cancer in Chinese population

Figure 4: Main effect factors of esophageal cancer in Chinese population

\begin{tabular}{|c|c|c|c|c|c|c|c|c|c|c|c|c|}
\hline & \multicolumn{3}{|c|}{ 1970-1975 } & \multicolumn{3}{|c|}{ 1990-1992 } & \multicolumn{3}{|c|}{ 2004-2005 } & \multicolumn{3}{|c|}{ 2011-2012 } \\
\hline & Total & Male & Female & Total & Male & Female & Total & Male & Female & Total & Male & Female \\
\hline $0 \sim$ & 0.00 & 0.00 & 0.00 & 0.00 & 0.00 & 0.00 & 0.00 & 0.00 & 0.00 & 0.05 & 0.12 & 0.00 \\
\hline $1 \sim$ & - & - & - & 0.00 & 0.01 & 0.00 & 0.00 & 0.00 & 0.00 & 0.00 & 0.00 & 0.00 \\
\hline $5 \sim$ & 0.00 & 0.01 & 0.00 & 0.00 & 0.00 & 0.00 & 0.00 & 0.00 & 0.00 & 0.01 & 0.00 & 0.03 \\
\hline $10 \curvearrowright$ & 0.01 & 0.01 & 0.00 & 0.01 & 0.02 & 0.01 & 0.00 & 0.00 & 0.00 & 0.01 & 0.04 & 0.00 \\
\hline $15 \sim$ & 0.06 & 0.06 & 0.05 & 0.07 & 0.09 & 0.05 & 0.03 & 0.05 & 0.00 & 0.00 & 0.00 & 0.00 \\
\hline $20 \curvearrowright$ & 0.20 & 0.23 & 0.16 & 0.17 & 0.18 & 0.17 & 0.12 & 0.11 & 0.13 & 0.09 & 0.12 & 0.01 \\
\hline $25 \sim$ & 0.44 & 0.50 & 0.38 & 0.37 & 0.44 & 0.29 & 0.15 & 0.20 & 0.10 & 0.14 & 0.15 & 0.11 \\
\hline $30 \sim$ & 1.35 & 1.60 & 1.09 & 0.99 & 1.30 & 0.66 & 0.31 & 0.43 & 0.18 & 0.26 & 0.37 & 0.15 \\
\hline $35 \sim$ & 3.57 & 4.37 & 2.73 & 3.28 & 4.34 & 2.13 & 1.13 & 1.63 & 0.61 & 0.76 & 1.21 & 0.51 \\
\hline $40 \curvearrowright$ & 9.63 & 12.16 & 6.92 & 8.31 & 10.24 & 6.18 & 3.57 & 5.40 & 1.66 & 3.12 & 4.56 & 1.78 \\
\hline $45 \sim$ & 21.44 & 27.66 & 14.86 & 17.92 & 22.99 & 12.32 & 8.59 & 13.51 & 3.43 & 9.13 & 15.30 & 4.14 \\
\hline $50 \sim$ & 42.83 & 56.38 & 28.76 & 32.08 & 41.67 & 21.56 & 20.46 & 31.03 & 9.34 & 21.29 & 33.85 & 8.96 \\
\hline $55 \sim$ & 70.77 & 94.58 & 46.61 & 56.32 & 74.58 & 36.60 & 36.99 & 53.49 & 19.54 & 44.68 & 69.42 & 21.36 \\
\hline $60 \frown$ & 109.06 & 149.84 & 70.04 & 95.36 & 126.52 & 62.49 & 56.01 & 78.36 & 32.10 & 73.87 & 108.61 & 41.23 \\
\hline $65 \sim$ & 142.97 & 198.02 & 93.56 & 131.04 & 177.19 & 86.20 & 81.07 & 114.50 & 47.27 & 95.46 & 134.04 & 58.66 \\
\hline $70 \sim$ & 186.11 & 260.18 & 125.75 & 176.74 & 248.19 & 114.58 & 123.15 & 176.27 & 72.69 & 120.73 & 168.05 & 74.74 \\
\hline $75 \sim$ & 180.19 & 248.56 & 128.90 & 173.96 & 250.86 & 116.05 & 154.02 & 217.39 & 100.35 & 141.54 & 191.70 & 93.68 \\
\hline $80 \sim$ & 182.15 & 238.82 & 146.35 & 177.69 & 255.76 & 130.44 & 180.55 & 259.82 & 123.40 & 179.92 & 210.77 & 151.95 \\
\hline & & & & 156.69 & 228.52 & & & 220.45 & & & 216.30 & \\
\hline All & 16.75 & 21.12 & 12.18 & 17.38 & 22.14 & 12.34 & 15.21 & 20.65 & 9.51 & 16.25 & 22.38 & 9.80 \\
\hline
\end{tabular}

Chen Xia [14] Studied 4132 patients (Barrett'sesophagus, BE) in 41 studies. The detection rate of BE is $2.39 \%$, which is lower than that reported by other countries $3 \% \sim 8 \%$. The ratio of men and women was 2.08:1. The average age of BE in China was 53.27 years old, earlier than that of the Europeans about 60 years old. The H.pylori detection results of 1775 cases of BE showed that the positive rate of H.pylori was $46.42 \%$, which was higher than that of $32.9 \%$ H.pylori reported in western countries. 
492/4132 was followed up for 13.7 months $\sim 4$ years, The incidence of carcinogenesis was $0.61 \%(6 / 984,95 \%$ CI=0.12 -1.10), which was slightly higher than that of $0.54 \%$ of the Conio report [15].

\section{Discussion}

Exposure to carcinogenic nitrites and fungal toxins significantly increased in residents of Lin Zhou. Conversely, a significant increase in vitamin A and B2 intake was observed during the same period. Protective factors including the use of cleaner drinking water and improved nutritional status also increased in prevalence [16-18]. However, although this information is useful, many factors that influence the occurrence of esophageal cancer remained to be elucidated. Wei's [19] and Haijun's [20] research groups analyzed 4,329 and 11,097 cases of postoperative clinical and pathological data pertaining to esophageal cancer patients, respectively. These groups reported that esophageal cancer occurred in several different sites including the cervical segment $(0.86 \%)$, the upper segment $(9.90 \%)$, the middle segment $(72.36 \%)$, and the lower segment (16.89\%) of the esophagus (Figure 5). The studies also revealed that these sites remained stable for 10 years. Squamous cell carcinoma was the main pathological type among the 4,329 cases of esophageal cancer that were analyzed (Figure 6).

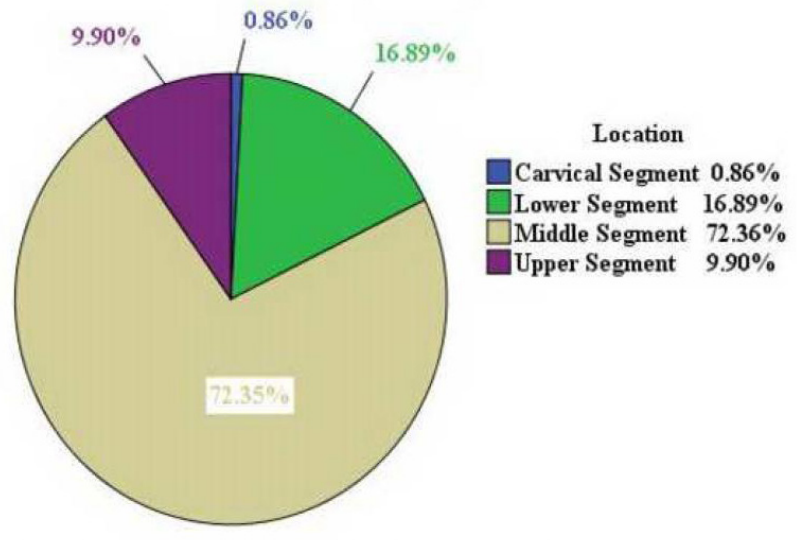

Figure 5: Esophageal cancer location constituent ratio

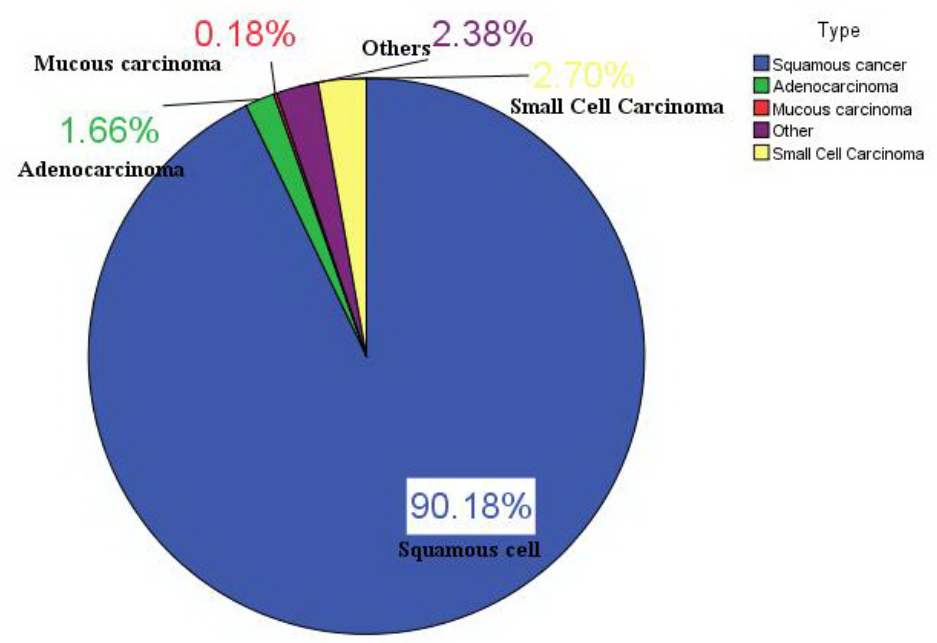

Figure 6: Pathological types of esophageal cancer in China

In the15, 204 cases of esophageal cancer with postoperative pathologies, cancer cell infiltration reached the deep muscular layer and invaded into the surrounding tissue, indicating that surgery was predominantly performed on individuals in the later stages of the disease (Table 3). Thus, earlier detection and intervention is critical.

\begin{tabular}{|c|c|c|}
\hline Depth of tumor invasion & Cases & Proportion \% \\
\hline Mucosa and submucosa & 837 & 5.51 \\
\hline Superficial myometrium & 594 & 3.91 \\
\hline Deep myometrial & 6045 & 39.76 \\
\hline Fiber Membrane & 7392 & 48.62 \\
\hline Outside & 336 & 2.21 \\
\hline Total & 15204 & \\
\hline
\end{tabular}




\begin{tabular}{|c|c|c|c|c|c|}
\hline Years & Author & Cases & $\begin{array}{l}\text { Incidence of } \\
\text { anastomotic } \\
\text { leakage \% }\end{array}$ & $\begin{array}{l}\text { Incidence of } \\
\text { anastomotic } \\
\text { leakage \% }\end{array}$ & $\begin{array}{l}\text { Five year } \\
\text { survival } \\
\text { rate } \%\end{array}$ \\
\hline 1994 & ShaoLingfang ${ }^{20}$ & 6428 & 3.6 & 2.3 & 40.4 \\
\hline 1996 & Xu Guangzhao ${ }^{21}$ & 2876 & 1.3 & 2.1 & 42.3 \\
\hline 1998 & Li Baotian ${ }^{22}$ & 2201 & 1.6 & 1.0 & 30.0 \\
\hline 1998 & Zhang Rugang ${ }^{23}$ & 5498 & 3.8 & 3.5 & 30.4 \\
\hline 2003 & Peng $\operatorname{Lin}^{24}$ & 356 & 0.8 & 0.0 & 55.5 \\
\hline 2005 & Ping Yumin ${ }^{25}$ & 11745 & 1.5 & 1.5 & 27.69 \\
\hline 2006 & Lv Yingyi ${ }^{26}$ & 576 & 1.9 & 0.3 & 49.2 \\
\hline 2009 & Wu Changrong ${ }^{27}$ & & 2.2 & 0.2 & 54.8 \\
\hline All & & $\frac{1690}{31370}$ & $2.57 \pm 1.087$ & $2.32 \pm 0.997$ & $43.95 \pm 10.247$ \\
\hline$p$ & & & 0.00 & 0.00 & 0.00 \\
\hline $95 \% \mathrm{CI}$ & $2.0095 ; 3.1390$ & $\begin{array}{l}1.6498 \\
2.9979\end{array}$ & $42.841 ; 45.0593$ & & \\
\hline
\end{tabular}

Table 4: Surgical treatment results of esophageal cancer

Surgery is the most common primary treatment for esophageal cancer. In 1941, Yingkai [23] described surgical approaches that were used to perform esophageal cancer resection in a Chinese population. These approaches included a left thoracic approach (Sweet esophagectomy); a right chest approach through the right portion of the thoracic esophagus; an esophagusstomach-right chest anastomosis of Ivor-Lewis-esophagectomy; McKeown-esophagectomy; and esophageal avulsion without thoracotomy. Since the 1990s, minimally invasive cancer esophagectomy (MIE) has gradually become a standard surgical strategy for esophageal cancer in China [24]. Analysis of data from all esophageal cancer treatment centers in China since 1994 shows that treatment of esophageal cancer is improving, and complications and mortality have significantly decreased; although associated survival rates are still not optimal (Table 4).

Preoperative TNM esophageal cancer staging for radical resection is an important step in facilitating the most optimal therapeutic strategies. However, this staging method is not sufficiently accurate and poses limitations with respect to diagnosis. Specifically, approximately $60 \%$ of patients have mismatched clinical and postoperative pathological stages and these discrepancies reduce overall mortality [21]. Computer tomography (CT), nuclear magnetic resonance (MRI), endoscopic ultrasonography (EUS), and thoracoscopy are used for preoperative staging and, among these EUS is the most optimal method for visualizing clear esophageal wall invasion and lymph node metastasis. A previous report demonstrated that T stage accuracy is $82.9 \%$ and $\mathrm{N}$ stage accuracy is $77.6 \%$ [22]. However, currently hospitals lack the necessary equipment to properly stage patients. Consequently, although the value of its use is questionable, positron emission tomography (PET) is often used for preoperative staging.

Currently [25], there is no significant difference in 5-year survival between the minimally invasive surgery and open chest surgery. A study of MIE data suggested that the average hospital stay was 9 days, Anastomotic leakage was $8.6 \%$, pulmonary complication occurrence was $9.5 \%$, the 3 -year survival rate was $58.4 \%$ and there was a local recurrence rate of $6.7 \%$. Thus, MIE is deemed to be relatively safe and may accelerate postoperative recovery. This strategy may also reduce hospital stays and postoperative complications, while also facilitating systematic lymph node dissection in a manner comparable to traditional open chest surgery. Robotic technology has been used for minimally invasive surgery and DaVinci surgery system-assisted esophageal resection has been attempted in China; however, high equipment costs preclude the widespread deployment of this resection strategy.

There remain several challenges in relation to the diagnosis and treatment of esophageal cancer. Among these, improving the accuracy of TNM staging and selecting more optimal tumor markers for early detection and treatment should be prioritized. Innovations in these areas would allow surgical treatment of esophageal cancer to be minimally invasive, personalized, comprehensive and standardized.

\section{Conclusion}

The comprehensive prevention and treatment of esophageal cancer is complicated and molecular biology and precision medicine will assist us to decrease mortality associated with this cancer. Fast-track surgery is beneficial for patient recovery. This approach has also been shown to improve the quality of life and reduce complications. Educational campaigns to raise awareness about potential causes of esophageal cancer will help to decrease resultant health care costs and mortality.

\section{Acknowledgement}

This work was supported by One Hundred Person Project of The Hebei Province (Project number: E2016100001). 


\section{References}

1. Li JY, Liu BQ, Li GY, Chen ZJ, Sun XI, et al. (1981) Atlas of cancer mortality from the People's Republic of China. Int J Epidemiol 10:127-33.

2. Chen WQ, Zheng RS, Zeng H, Zhang SW (2016) The incidence and mortality of malignant tumors in China in 2012. Chin J Cancer 25: 1-8.

3. Zhang ZX, Li BY, Guo CC (1994) Comparative analysis of epidemic trend of esophageal carcinoma in Linxian. HeNan Med Res 3: 251-256.

4. He TQ, Wei WQ, Rong SD (2007) Advances in cancer research in China. Beijing: Peking University Medical Press. 8: 3-15.

5. Wang JZ (2000) Development and achievements of the research teams in the prevention and treatment of esophageal cancer. Research on the history of cancer in China. Beijing: Military Medical Science Press 1: 75-91.

6. Li LD, Lu FZ, Zhang SW (1997) The 20 year trend of mortality of malignant tumor in China and the recent forecast analysis. Chin J Oncol 19: 3-9.

7. Zou XN, Lu FZ, Zhang SW (2002) Distribution characteristics of esophageal cancer mortality in China in 1990-1992. Chin Cancer 11: 446-9.

8. Li LD, Lu FZ (1996) Analysis of epidemic distribution of malignant tumor mortality in China during 1990-1992. Chin J Oncol 18: 403-7.

9. Wei WQ, Yang J, Zhang SW, Chen WQ, Qiao YL (2010) Analysis of the esophageal cancer mortality in 2004-2005 and its trends during last 30 years in China. Chin J Prev Med 44: 398-402.

10. Yamaji T, Inoue M, Sasazuki S, Iwasaki M, Kurahashi N, et al. (2008) Fruit and vegetable consumption and squamous cell carcinoma of the esophagus in Japan: the JPHC study. Int J Cancer 123: 1935-40.

11. Zhang QF, Gao YX, Wu DW, et al. (2004) Meta-analysis of influencing factors on the incidence of esophageal cancer. Chin Cancer 13: 277-79.

12. Zhou XQ, Li M, Huang CY (2011) Meta-analysis of main dietary factors on esophageal cancer in Chinese people. Moder Prev Med 38: 1207-10.

13. Zhang DH, Shen ZY, Yi Zhu, et al. (2009) Meta-analysis of relationship between tumorigenesis of esophageal carcinoma and human papillomavirus infection. ShijieHuarenXiaohuaZazhi 17: 1130-4.

14. Chen X, Zhu L, Hou Xh (2008) Metaanalysis of 4132 cases of Barrett's esophagus in China. Chin J GastroenterolHepatol, 17: 102-5.

15. Conio M, Blanchi S, Lapertosa G, Ferraris R, Sablich R, et al. (2003) Long term endoscopic surveillance of patients with Barrett's esophagus.Incidence of dysplasia and adenocarcinoma: a prospective study. Am J Gastroentero 98: 1931-9.

16. Yang WX (2008) Observation of the effect of prevention in the high incidence area of esophageal cancer in Linzhou, China. Chin Cancer 17: 548-52.

17. Wei DG, Wang SJ (2008) The Implications of Centralized Occurrence of Upper Gastrointestinal Carcinomas in a Region at High Risk for Esophageal Cancer. Chin J Clinical Oncol 35: 1150-3.

18. Qiao YL, Dawsey SM, Kamangar F, Fan JH, Abnet CC et al. (2009) Total and cancer mortality after supplementation with vitamins and minerals: follow-up of the Linxian General Population Nutrition Intervention Trial. J Natl Cancer Inst 101: 507-18.

19. Wei Liu, Xishan Hao, Ying Jin, Haixin Li, Linan Song et al. (2008) Analysis of Clinicopathologic Features of Esophageal Cancer Patients after Surgery-a Report of 4,329 Cases. Chin J Clinical Oncol 35: 241-4.

20. HJ Yang, SS Zhang, ZS Xiao, et al. (2003) Clinicopathological analysis of 11097 resected specimens of esophageal carcinoma. Chin Cancer 12: $264-265$.

21. RG Zhang (1999) Current status and progress of surgical treatment of esophageal carcinoma. Chin Cancer 8: 28-9.

22. Wu YK, Huang GJ, Shao LF, et a l. (1982) Progress in the study and surgical treatment of cancer of the esophagus in China, 1940 -1980. J ThoracCardiovascSurg 84: 325 - 33 .

23. Law S, Wong J (2002) Use of minimally invasive oesophagectomy for cancer of the esophagus. Lancet Oncol 3: 215-22.

24. Guo W, Ma X, Yang S, Zhu X, Qin W, et al. (2015) Combined thoracoscopic-laparoscopic esophagectomy versus open esophagectomy: a meta-analysis of outcomes. Surg Endosc 30: 3873-81.

25. Luketich JD, Pennathur A, Franchetti Y, Catalano PJ, Swanson S, et al. (2015) Minimally invasive esophagectomy: results of aprospective phase II multicenter trialthe eastern cooperative oncology group (E2202) study. Ann Surg 261: 702-7.

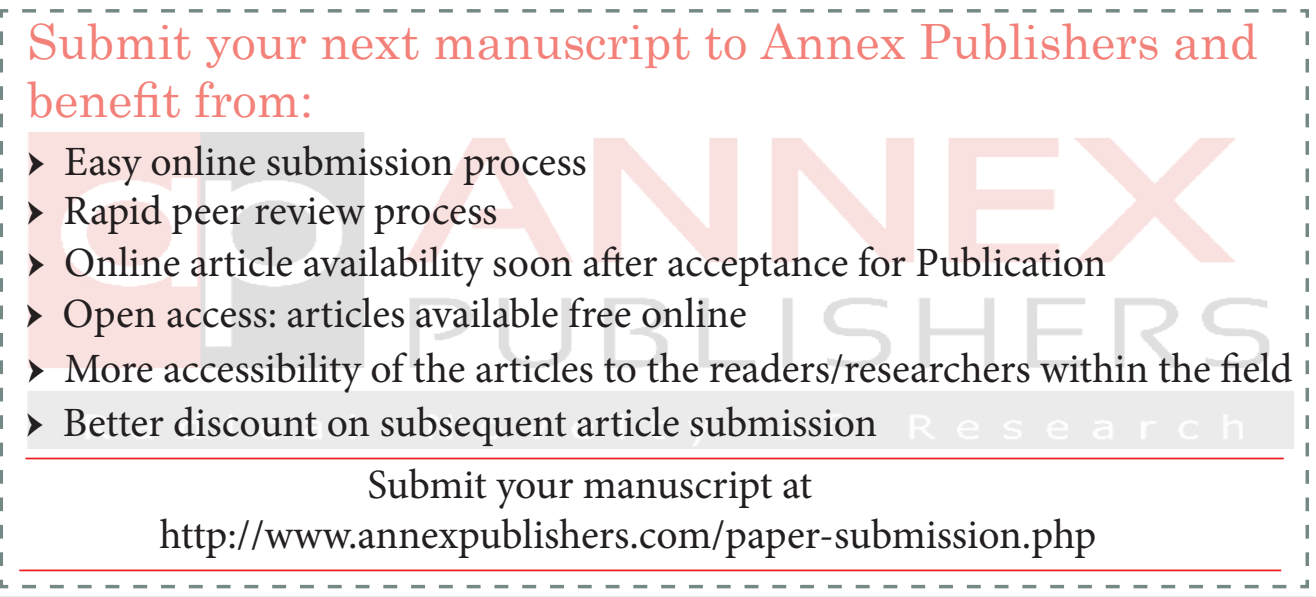

